\author{
Adam M. Deane \\ Gordon H. Guyatt
}

\section{Trials on stress ulcer prophylaxis: finding the balance between benefit and harm. Response to Krag et al.}

Accepted: 8 May 2015

Published online: 19 June 2015

(C) Springer-Verlag Berlin Heidelberg and ESICM 2015

Related correspondence can be found at: doi:10.1007/s00134-015-3860-8.

Dear Editor,

We thank Dr. Krag and colleagues [1] for their comments. The authors concur with us regarding the need for further evidence to establish or refute the desirability of stress ulcer prophylaxis for critically ill patients.

The logic underlying the choice of trial design depends on one's belief regarding the trial evidence and current convictions about the usefulness of stress ulcer prophylaxis. The authors believe that the evidence supporting the benefit of prophylaxis in reducing bleeding warrants low confidence, but that the intervention may impact on mortality, and that a trial evaluating the superiority of placebo is warranted.

Our assessment is that the evidence supporting a reduction in clinically important upper gastrointestinal bleeding with prophylaxis warrants at least moderate confidence. Given the routine acid suppression in many ICUs [2, 3], and incorporation of this approach in practice guidelines [4], it appears that the critical care community shares our assessment of the existing evidence. We therefore suggest that the key issue is whether the magnitude of effect on clinically important upper gastrointestinal bleeding from stress ulcer prophylaxis is sufficient that it warrants continued use, particularly given risks and costs [5]. If this is the question, a non-inferiority design is appropriate.

Regarding the choice of outcome for a trial of stress ulcer prophylaxis: if prophylaxis does influence mortality, we anticipate that the difference is extremely small [6], such that the target sample size suggested by these authors for a trial addressing mortality represents an underestimate. Whether ascertaining the impact of prophylaxis on upper gastrointestinal bleeding - the outcome that stress ulcer prophylaxis is designed to prevent-is a worthwhile endeavour is a matter of judgment. Our conviction is that given the widespread current use of prophylaxis, and the uncertainty associated with its impact, such a trial is warranted.

Conflicts of interest On behalf of all authors, the corresponding author states that there is no conflict of interest.

\section{References}

1. Krag M, Perner A, Wetterslev J, Wise MP, Møller MH (2015) Trials on stress ulcerprophylaxis: finding the balancebetween benefit and harm. Intensive Care Med. doi: 10.1007/s00134-015-3860-8
2. Krag M, Perner A, Wetterslev J, Wise MP, Borthwick M, Bendel S, McArthur C, Cook DJ, Nielsen N, Pelosi P et al (2015) Prevalence and outcome of gastrointestinal bleeding and use of acid suppressants in acutely ill adult intensive care patients. Intensive Care Med 41(5):833-845. doi:

10.1007/s00134-015-3725-1

3. Eastwood GM, Litton E, Bellomo R, Bailey MJ, Festa M, Beasley RW, Young PJ (2014) Opinions and practice of stress ulcer prophylaxis in Australian and New Zealand intensive care units. Crit Care Resusc 16(3):170-174

4. Dellinger RP, Levy MM, Rhodes A, Annane D, Gerlach H, Opal SM, Sevransky JE, Sprung CL, Douglas IS, Jaeschke R et al (2013) Surviving Sepsis Campaign: international guidelines for management of severe sepsis and septic shock, 2012. Intensive Care Med 39(2):165-228. doi: 10.1007/s00134-012-2769-8

5. Deane AM, Guyatt GH (2015) Primum non nocere and challenging conventional treatment. Intensive Care Med 41(5):933-935. doi: 10.1007/s00134-015-3785-2

6. Krag M, Perner A, Wetterslev J, Wise MP, Hylander Moller M (2014) Stress ulcer prophylaxis versus placebo or no prophylaxis in critically ill patients. A systematic review of randomised clinical trials with meta-analysis and trial sequential analysis. Intensive Care Med 40(1):11-22. doi:

10.1007/s00134-013-3125-3

A. M. Deane

Discipline of Acute Care Medicine, University of Adelaide, Adelaide, SA, Australia

A. M. Deane (

Department of Critical Care Services, Royal Adelaide Hospital, Adelaide, SA, Australia e-mail: adam.deane@adelaide.edu.au

\section{G. H. Guyatt}

Departments of Clinical Epidemiology and Biostatistics and of Medicine, Faculty of Health Sciences, McMaster University, Hamilton, ON, Canada 